be harmful in the future when the period of present cheap money is past.

Another present-day aspect of medical student life which personally I much regret is the innovation of political student societies. It is a tradition of British Medicine, as it is of the British Red Cross, that our service is independent of political creed. The doctor should be entirely impervious to political influences. His concern is with the great essentials of birth, life, and death, which transcend all other considerations, and he should resolutely turn his back to the rival claims of political factions both at home and abroad.

\section{Faults in Medical Education}

In the present wave of optimistic post-war planning it was not to be expected that the perennial subject of medical training would escape the infection. It is well that this should be so, for it is obvious to most of us who are responsible for the teaching of clinical medicine that our present methods fall short of what is desirable, or in fact necessary, to equip the student for the world in which he will carry on his life's work after he leaves his "Alma Mater." The main object of our medical schools should surely be to produce the finest type of that traditional and honoured symbol of British medicine to which I have already referred-viz., the family practitioner. Are we doing that to-day? It appears to me that the whole system of our medical training requires revision, and therefore I welcome the fact that an Interdepartmental Committee on Medical Schools is already at work on this important matter. A major fault in our present medical education is the lack of cohesion between those responsible for welding the individual parts of the finished machine. Each teacher and each department, influenced no doubt by the advance of knowledge and anxious to communicate that knowledge to their students, overweight their subject with a mass of detail that can only harass the student mind and increase his anxiety as the examination time approaches. The pre-clinical teachers, endeavouring no doubt to establish a sound framework upon which modern clinical medicine can be built, try to crowd more and more into their lectures and classes. The surgeon makes his dressers stand long hours and witness tiring operations which the majority will never be called upon to perform. The clinical physician asks for the attention of his clerks while he discusses the intricate and highly scientific details of some knotty problem which most of his audience may never meet. The result of all this is that the average student finds himself qualified, and launched into a world which offers a strange contrast to the one where he has been educated. Shock No. 1 will be the revelation that concentrated scientific knowledge is not the only, or indeed most important, asset when in contact with his fellow-men and patients. He will find that he must be a human being first, and a doctor after. Shock No. 2 when he enters practice will be the discovery that he may not have available the necessary adjuncts for the application of all that he has learnt. There are other shocks in store for him, but let us hope that they will be fewer when the work of the Planning Commission reaches fruition.

To convert some of my criticism into practical politics, is it not possible for those responsible for the organization of medical training to envisage a more generalized and less comprehensive course of teaching than that now in being? Let there be in medicine a "School-leaving Certificate" at the end of, say, a five-years curriculum, as distinct from a "Higher School Certificate" awarded at the end of a further year's training devoted to some special aspect of medical work. Certificate $A$ would not entitle the holder to the independent practice of his profession, but it would qualify him to become an assistant in family practice or in any of the special aspects of medicine which appeal to him. At the end of a further year's work he would secure Certificate B-i.e., the higher qualification-which would launch him upon his life's work. The concept of attaching a Certificate A student to a doctor engaged in the work of general practice appeals to me as a modern counterpart of the old apprenticeship system. The young man fresh from hospital would gain the experience he now lacks and learn to appreciate the fact that in life it is not so much what one does as how one does it. On the other hand, the older family practitioner would constantly be in touch with the vitalizing stimulus of the young and active scientific mind. Surely nothing but good could evolve from the liaison.

\section{Prospects in Medical Practice}

And, finally, what prospects have we to offer to the medical man or woman of the future? If the major proposals of the Planning Commission are accepted in principle and duly implemented I think we may safely say that many of the difficulties under which the profession now works will have been removed. The doctor of the future will have the satisfaction of doing good work with the increased facilities that are available to him; he will be better able to apply to his patients those methods of diagnosis and treatment which he was taught during his student years; and, finally, owing to the coordination of all the various health services, he will know that he forms an integral part of a great organization whose sole object is to maintain the health and happiness of the nation it serves.

My theme to some may have appeared retrogressive or irritating. I can only reassert my personal conviction that, whatever " new order" may arise in the conduct of medical practice, the future happiness of our people is intimately bound up with the maintenance of our British tradition in medicine that a patient is a patient and not an impersonal unit in a system.

\section{MALINGERING}

BY

\section{RANKINE GOOD, M.B., Ch.B., D.P.M. Captain, R.A.M.C., Graded Psychiatrist}

The brief references to malingering (the conscious adoption and exploitation of symptoms of illness, physical or mental) in standard textbooks of medicine may be regarded as silent testimony to the rarity with which the condition is encountered in civil life. On the other hand, there may be lack of interest in the subject or difficulties in the clinical approach.

I have met with three civilian cases. The first was that of a vagrant to whom the prospect of a sound night's sleep with an assured breakfast to follow was sufficient motive: some months previously he had undergone a three-weeks investigation at the same hospital for his alleged gastric complaint and had been dismissed at the end of that time as a case of functional disorder: he hinted vaguely that identical investigations had been performed at other hospitals in the interval between his two admissions, with similar results. The second case was also that of a vagrant, similarly motivated, who trafficked on his habitual pallor and prematurely senile appearance to secure admission to hospital for investigation as a potential anaemic. In the third case the man, like the schizoid Hamlet, was resolved to "put an antic disposition on" in an endeavour to, in his case, escape from the pressing attention of the police for illegal misappropriation of money. These three were clearly abnormal people. Other cases are occasionally encountered (particularly in connexion with alleged injuries-of which no evidence shows-sustained in motor-car accidents) in which the diagnosis of malingering cannot be applied, solely through the lack of a confession to that effect from the "patient," whose desire for monetary gain overrides his truthfulness : these cases, of course, are altogether distinct from the genuine traumatic neuroses occurring in the same circumstances.

\section{Wartime Cases}

In wartime, perhaps because of the importance of morale and discipline, more frequent references to malingering appear in medical literature, although it is generally assumed that, so far as the war of 1914-18 was concerned, it was of rare occurrence (War Office Report, 1922a). Hurst (1940) lays down two criteria for the certain diagnosis of malingering-either detection in flagrante delicto, or an unforced confession from the man in accordance with the facts observed. The methods adopted by malingerers vary: a comprehensive account of these is given by Buinewitsch (1941).

In the examination of neurotic patients the physician often adopts a too confiding attitude, or, on the other hand, a 
too sceptical attitude which confounds the hysteric with the malingerer. In the hysteric, the production of conversion symptoms is motivated and effected without clear recognition by the patient of the processes involved. Similarly, while undoubtedly the hysteric in the Services does tend to exploit his symptoms more than he did in civil life (e.g., reporting sick with his complaint every day since conscription, whereas he attended his civilian medical practitioner once fortnightly or monthly), this exploitation is seldom recognized by the patient, however apparent the underlying motivation may be to the observer. It is well to bear this in mind; for, as a consideration of Case VI will show, malingering may be a mere incident during a schizophrenic episode occurring in a mental defective: further, the symptom produced by the malingering may be followed by the development of hysterical symptoms in the affected part. The explanations of malingering hitherto given disregard such things as the malingerer's choice of symptoms and the basic personality structure and attitude which allows him to malinger.

This communication may be regarded as a contribution to the solution of these problems. To this end, 6 cases will be quoted and points common to all of them discussed. Only the relevant details are given.

\section{Case I (Psychopathic Personality)}

At his entrance medical examination this man had turned up with the external auditory meati plugged with facecream in an endeavour to feign deafness, and he had pretended idiocy when asked to read the Snellen test types. Actually his mental age was $125 / 12$ years. An officer of his battery stated: "Sympathy and help did not have the desired effect of improving his work. ... He became persistently worse ... . started the habit of grumbling and leaving fatigues when not under supervision .... and has no desire to soldier." The M.O. stated that the patient was always reporting sick, made contradictory statements, was unappreciative of help, and would not co-operate. On admission to hospital the man was quite frank with me when I asked him if he was "swinging the lead." He informed me that he had a horror of bloodshed, and for that reason had by his malingering wished to avoid conscription four months previously. His previous history showed that he was an aggressive individual, had had marked phobias in infancy and childhood, and since leaving school, at which he was backward-most probably through inattention and an absence of any desire to learn - he had, between lengthy spells of unemployment, been in several jobs which he left because the work was " too hard" or "too monotonous." On one occasion he was sacked because he left his work " to go out and have a drink." He attributed all his troubles, past, present, and to come, to his wife, who he said had made a cuckold of him, and to his mother-in-law, who was a devil's dam. He spoke of them with an angry display of emotion which left him incoherent and speechless. He concluded by saying that life was not worth while in the circumstances, and that suicide as a way out was under contemplation. I agreed with him that suicide in his case would offer the best solution to his difficulties, and suggested simple methods whereby he might accomplish this effectively and undisturbed. Much taken aback, he rejected all I had said to him by stating that he had never given the subject a thought. As with his malingering, he was again shamming.

\section{Case II (Psychopathic Personality)}

This patient had been in two hospitals for 11 days before his transfer as a case of functional condition. He had had what was apparently a genuine fainting attack, after which he was admitted to hospital in a stuporous condition, with a pulse rate of, on one occasion, 48 a minute. When he came-to 4 days later there was a weakness of his left side. When I first saw him this weakness consisted of what I took to be hysterical paralysis of his left hand, in no way differing from other similar paralyses I have seen-dusky blue, swollen, cold and clammy. Circumstances precluded any treatment at the end of his first interview save the reassurance that I was satisfied from my examination that there was no structural disability which would account for the appearance and complete powerlessness of his hand. He had merely lost the idea of how to use it. It was up to him to accustom himself to the idea that his hand was perfectly normal and capable of use and that a decided improvement would be evident on the next occasion I saw him. Such improvement was, however, not forthcoming. I then attempted some very superficial interpretation from the point of view of motivation, reminding him of his statement.
"I don't like the Army, and never will," made during the previous interview, and how he might have had, unawares and in the depths of his mind, developed the symptom of a paralysed hand as an excuse, as it were, for his discharge. I also pointed out to him how this method of being quit of the Army was probably suggested to him by a similar affection he had had seven years previously (of which he had previously informed me), when, working as a tea-boy to builders, his right hand had contacted a live wire; and how, following his 12 -ft. fall when the current was switched off, the left side of his face was temporarily paralysed and he had been awarded compensation for 10 or 11 weeks thereafter. At this point the patient showed an apparent and considerable resistance to my interpretation, getting up as if making to go out and bitterly complaining that after three weeks in hospital he had received no treatment. He asked to be returned to his unit. I then pointed out the ridiculousness of his request with his present disability and how the three weeks in hospital had been valuable in that it had enabled the medical officers concerned to arrive at a true estimate of his disability-a very big step forward indeed in treatment and progress. This progress was now being held up solely because of his own attitude, which precluded his acceptance of a psychic origin for the disability. Further, he would continue to receive treatment and would not be permitted to leave hospital until he was entirely cured. At this point, and with rather a strained expression, he confessed he could use his hand perfectly, proceeding to do so at my request. I asked him if he were aware of the fact that he had been malingering and of the possible consequences that might follow upon his confession; he said that he was.

His previous history revealed a habitually quiet self-conscious personality who had always avoided games and social intercourse on account of his shyness and habit of blushing. He had had phobias associated with darkness and heights; and at school, where he was slightly above the average (his M.A. was $13 \cdot 10 / 12$ years), he had never been in any school fights He had always sought, and expected, "pity and sympathy from other people."

\section{Case III (Psychopathic Personality)}

This man said that he had been very nervous when young, and cited as an instance of this, "If someone hit me 1 wouldn't have the nerve to hit him back." He had pronounced phobias associated with darkness, deep water, heights, and dogs. He was very shy, was a lifelong nail-biter, and suffered from nocturnal enuresis until he was. 21 years old. At school, where he said he was backward (his M.A. was 11 11/12 years), he was never in any school fights, was bullied, and avoided sports. He first came into contact with the civil police when he was 10 years old for stealing: for this he served 15 weeks in a reformatory. Since then he had been seven times charged and convicted, chiefly for receiving, the last term of imprisonment being for eight months. After serving this, he felt: "If I didn't join up" (one month before the outbreak of war) "I would be in Dartmoor before long." Since joining he had been seven times charged with absence without leave.

When he first reported sick he presented what might have been taken for symptoms indicative of an anxiety neurosis. I was sceptical about the genuineness of his complaints, particularly since he was again awaiting trial for absence without leave. An unforced confession was ultimately obtained that he was malingering with the object of escaping trial or obtaining a recommendation for mitigation of sentence on medical grounds.

\section{Case IV (Mental Defective)}

Even before admission this man was suspect, his admission notes stating that "the act may have been committed to get away from the place." "The place" was a lonely spot on a loch-side to which four corporals and he had been posted to open up a station. Fed up, he said, with the complete lack of social life, not helped by the four corporals keeping to themselves (from the facts available he did not appear to be paranoid about this), he walked into the loch in a feigned attempt at suicide in order to get away from the place. Similarly. when shaving, he had made a great display of his razor. His mental age was $105 / 12$ years.

\section{Case V (Psychopathic Personality)}

Admitted with a history of having given himself up after nine months' absence without leave and pleading loss of memory for the lapse. He persistently maintained that his loss of memory was genuine or that it was at times partial, permitting him to get married and to wander around in his battle-dress (despite the fact that he had no ration cards) doing odd jobs. His story was so grotesque that his statements were 
accepted with some reserve. Ultimately he confessed that his story was fabricated." He had become " fed up and couldn't stick it" (the Army), purposely deserting to return to his civilian job on a trawler (on which, incidentally, he had made a voyage to Iceland), marrying during one of his spells on shore, and ultimately giving himself up on his wife's advice. His M.A. was $1411 / 12$ years.

\section{Case VI (Schizophrenia)}

Was admitted to a general hospital for eight weeks for treatment for an attack of gonorrhoea. During this period he had become depressed ("fed up") on account of all his articles being marked and his having to spin unconvincing stories to his fellow patients (by whom he said he was ultimately shunned) as to why he was so discriminated against. His attitude when he came out of hospital was: "If you're not good enough to mix with people you're not good enough to soldier with them." One week after his discharge from hospital his rifle, which he was hurrying to put away in order to get to tea, discharged accidentally, the bullet going through his left great toe. He himself had not loaded the rifle, nor did he understand how it came to be loaded. Expatiating on his attitude to the Army, he said, "I never did care for the Army," in which he was slow at "picking things up." His mental age was $87 / 12$ years. Concerning his previous history, he said he had always been nervous and had phobias associated with darkness and loneliness, and if ever he found himself in such circumstances was afraid he might be attacked from behind. $\mathrm{He}$ also had phobias associated with water, heights, cows, and horses; he was a lifelong nail-biter, was shy blushed easily. and said, "I kept myself to myself, more or less": he was a "mother's boy," Hysterical symptoms had supervened in connexion with the gunshot wound of his foot: there was moderate degree of cyanosis and paralysis, due, he said, to pain associated with the healed wound which caused him to limp.

It was not until these hysterical symptoms were removed with treatment that he confessed to the previous existence of auditory hallucinations which made h'm think he "was going soft." His attitude towards the Army, the unbearable going tion from his mother, and his auditory hallucinations all combined to make him thoroughly "browned off," in which state of mind (he now confessed) he shot himself through the great toe in an endeavour to be quit of the Army and to be returned to the home life in which the care and sympathy he needed would be forthcoming. (It should be noted that his hallucinations had no bearing on his deliberate conscious hatlucinaavoid service by shooting himself-e.g. the men's voices he heard holding everyday conversations did not tell him to shoot himself.)

\section{Analysis of the Cases}

From a study of these cases, of which only brief details have been given, certain aspects of malingering emerged conspicuously.

In the first place, the choice of symptom (i.e., insanity, paralysis, gunshot wound, or amnesia) was apparently largely determined by unrecognized emotional factors rather than by any intellectual process. In all cases save Case II no reason for the choice of symptom was given other than "It was all I could think of," "I don't know," etc. Case II, after stating that his "paralysed" hand might have been suggested by his previous accident, subsequently said that he doubted verv much if that were the real reason. Since no analytical treatment of these cases was attempted it is perhaps unwise to speculate as to what the factors determining the choice of symptom were. Nevertheless, it was very noticeable that all cases (including Case I-only superficially aggressive) clearly showed a mental attitude in which a desire, a thirst for punishment, was dominant, though the patient himself was unappreciative of the existence of this desire. The point was well illustrated in Case III-his having been bullied at school because he was afraid to hit back, his repeated trouble with the police and subsequent punishment, and finally his attempt to escape from them by volunteering for an organization which has discipline and unquestioning obedience for its mainstays, an organization which, following a short period of service in 1927, had discharged him after he had served 56 days' detention for absence without leave. His phobias had also been used as vehicles for punishment - e.g., despite his dread of water he had worked for a spell on a tugboat until he fell into the water "by accident" (he was a non-swimmer): and, despite his dread of heights, he had worked for a spell as a riveter's mate until he fell "by accident" down the hold of a ship under construction.
They also led him, after his discharge, to return to a city which has been repeatedly and heavily bombed, despite the fact that during a previous leave he had sustained slight physical injury during a "blitz" then in progress-a city in which his old temptations are awaiting him.

Closely associated with this desire for punishment, a marked attitude of infantile dependence was present in all cases, well illustrated in Case II, who had always sought and expected "pity and sympathy from other people," and in Case VI, whose desire to return to his mother amounted to a craving. This attitude was pronounced in Case I, who was desperate to get home to look after his mother although he was a married man with a wife and child. It is no digression from my theme (indeed, it is fundamental) to expand this point concerning the patients' attitude towards mothers whom absence has tended to idealize. Not infrequently, in actual fact, the mother has beaten and in other ways has psychologically misunderstood and mistreated the patient from his earliest days. This is of very frequent occurrence in psychoneurotics. The craving for "the good mother" is usually quite open and apparent in those of low mental age, and is concealed, disguised, and rationalized in more intelligent patients. The desire to be near the mother is remarkable in that while it is very real it is apparently unreasonable; for, on inquiry in all such cases that I have examined, it is found that the mother is quite capable of looking after herself and is suffering from no untoward domestic, pecuniary, or other distress.

Further inquiry elicits the fact that this desire on the part of the patient is not by any means of recent origin but has exerted itself with the same abnormal intensity and persistence as long as he can remember. As I have already said, it does not always show and has not always shown in an open longing for the good mother. It may show instead in a deep attachment to and affection for her house and home, etc., or to the wife, who frequently is an obvious mother-substitute. This attitude is natural up to a point, but in the cases under discussion it is quite pathological. It is no exaggeration to say that these patients are still psychologically united to their mother by an emotional "umbilical cord," the forceful severance of which produces the most intense anxiety, which he is constitutionally incapable of mastering adequately. In other words, however much the psychoneurotic conveys the impression that he is fully adult, he still remains emotionally immature. The terrified scream of an infant when faced with a danger that appears overwhelming may have as its adult variant the blind panic of a man who exposes himself to the fire of his own guns during an enemy bombardment: in moments of stress he tends to revert to a state of infantile helplessness, a terrified bewilderment-a state exerting the most pernicious influence on his fellow soldier, whereas it is expected of him that he will " acquire such a standard of morale as will enable him to put the welfare of his unit before his own personal safety" (War Office Report, 1922b).

The second aspect which emerged conspicuously from the study of these 6 cases was that all showed an entire absence of guilt-feeling in connexion with their malingering-entirely different, if such a thing could be imagined, from what would occur in a well-adjusted personality who resorted to such methods. Now, the absence of guilt-feeling in circumstances in which a normal person would experience it is the hall-mark of the psychopath. The term "psychopath" is used in this instance in the very narrow sense as defined by Henderson (1939)-briefly, the existence of a peculiar state of mind which does not render the patient certifiably insane, which causes him to exhibit conduct of an antisocial or asocial nature, and on which treatment or punishment has no deterrent effect. (The discrimination between the psychopath whose intelligence is average or above and the moral imbecile who is of low intelligence would seem to be purely arbitrary: fundamentally, the psychic attitudes and reactions towards their environment and its problems are the same in both cases.)

In the third place, all 6 cases showed a pronounced anxiety concerning military service, the extent of this anxiety being out of all proportion to the circumstances engendering it. Their malingering was, indeed, an endeavour to overcome this anxiety by the simple expedient of attempting to remove themselves, by the simulation of symptoms, from the circumstances which gave rise to the anxiety. 


\section{Disposal of the Malingerer}

So far as the relation of the malingerer to the Army is concerned, it is essential to consider two points. The first of these is that the man's absence of guilt-feeling concerning his malingering leads to punishment or treatment having no deterrent effect on the future repetition of such conduct. The second point-and this is of the utmost importance in wartime-is the repercusșion which the malingerer's conduct and mental attitude may have upon his Army comrades and, through them, upon military efficiency in general. It has already been pointed out that the malingerer is in a state of extreme emotional immaturity. Consequently, he has broken down in adult circumstances which were successfully withstood by his more strongly constituted brothers-in-arms. In these circumstances he reverts to a state of open childishness. $\mathrm{He}$ may grumble and grouse: his work, his adult capacity for work, falls off ; he continually reports sick and is unappreciative of and does not co-operate in the treatment prescribed; he becomes a burden to all with whom he comes in contact in the environment for which he has a phobic anxiety; he develops the craving to return to his home, where the only real security he knows of is to be found and where his childish immaturity is understood and the pity and sympathy he has always expected from other people are forthcoming.

All this is clear and understandable, and in peacetime one could leisurely endeavour to wean such a case to a more adult independent state. When, however, he is a member of the fighting Services, and when the interests of the individual have of necessity to be subordinated to the group, this is out of the question. It is demanded of him that he "become a man" and "put away childish things"-which he is constitutionally incapable of doing. In his behaviour and attitude he is expected to contribute to the promotion and maintenance of good morale, instead of which he mopes about his group a potential and extremely dangerous menace to good morale in the more susceptible (i.e., the more emotionally immature) of his as yet mentally healthy comrades. Infectivity in these circumstances is as real a threat as the potential infectivity of a typhoid carrier in the physical sphere, as Wittkower et al. (1941) point out.

This constant and dangerous menace to good morale is, in effect, the crux of the matter concerning the disposal of the psychopath of this type in wartime. The report of the unit officers in referring the man to the R.M.O. when ordinary methods of producing correction have failed eloquently testifies to this. The paramount importance of the maintenance of excellent morale among soldiers has been appreciated from the earliest times, as also has its obvious remedy-namely, the ruthless weeding out of all influences adversely affecting morale. Such a view was arrived at by considered inquiry in 1922: "The occurrence of the [psychoneurotic] conditions militates against the efficiency of the Army, swells the sick returns, increases the amount of hospital accommodation and transport required, and absorbs the time and attention of the medical personnel" (War Office Report, 1922c).

The continued presence of these people in any unit thus tends to promote a vicious circle-infection by the psychoneurotic and the psychopath of the more mentally immature of previously mentally healthy subjects, with increase of further frank psychiatric cases and a further lowering of morale. And the morale of an army is a barometer by which the fighting efficiency of that army can be read at a glance.

The removal of a weak link in an otherwise strong chain designed purposely to bear an enormous stress therefore requires no apology. Nor is it, as some might. imagine from a hasty assessment of facts, an admission of culpable failure. The psychiatrist, like the surgeon, can radically treat only those growths that are not beyond the reach of his therapeutic knife. In such cases, however, the psychiatrist is potent, from the prophylactic point of view, in removing a dangerous source of infection. Thereby he contributes not inconsiderably to the promotion of that morale and efficiency in the absence of which a fight is never won.

\section{Summary}

The malingerer is a psychopath with, among other features, a complete absence of guilt-feeling concerning his malingering.

Although he consciously assumes and exploits symptoms of physical or mental illness, the variety of symptom adopted (i.e., whether amnesia, gunshot wound, insanity, or paralysis) is, however, apparently determined by an unrecognized masochistic and very infantile dependent attitude.

Malingering is a defence mechanism employed by a constitutionally weak ego against a real but unreasonable and intense anxiety concerning military service.

The disposal of the malingerer in wartime should be preeminently determined by considerations of military morale and efficiency.

I am indebted to Lieut.-Col. R. J. Rosie, R.A.M.C., for encouragement and permission to pursue these investigations, and to Major J. P. McGuinness, R.A.M.C., for his assistance in Case III and the details concerning his Case V. To both, and to Major T. F. Rodger, R.A.M.C., I am beholden for their constructive criticism of the script of this paper.

REFERENCES

Buinewitsch, K. (1941). Methods of Malingerers summarized in Bulletin of War Medicine, 1, 283.

Henderson, D. K. (1939). Psychopathic States, p. 18, London.

Hurst, Sir A. (1940). Medical Diseases of War, p. 16, London.

(1922b) p. 190; (1922c), p. 169 (0)

Wittkower, E., Rodger, T. F., and Wilson, A. T. M. (1941). Lancet, 1, 531.

\section{FOREIGN BODIES IN THE ALIMENTARY TRACT}

\section{BY}

\section{G. O. CHAMBERS, F.R.C.S. \\ Visiting Surgeon to H.M. Prisons}

When Nature has provided so many problems in surgery to occupy scientific attention it seems inconsiderate that man should, by accident or otherwise, go one further by self-mutilation in the swallowing of foreign bodies. These cases, however, tend to provide compensations in the element of surprise and the interest they arouse, and create an atmosphere akin to the treasure hunt until such time as the quarry has been unearthed or retrieved. The excitement of all this inclines to be somewhat tempered by the fact that the majority of these perverse individuals are of dubious use to society and, moreover, in some cases develop a morbid appetite for foreign bodies. For some strange reason they seem to stand abdominal section well and develop peritoneal antibodies that serve them to such good purpose that either septic complications are avoided or their relative dangers are overcome.

This paper refers chiefly to intentional swallowing and not to cases of accident occurring usually in children and normal adults, with whom small articles swallowed-inadvertentlyhave a safe passage. The open safety-pin, fish-bone, or needle may cause trouble by impaction or perforation and necessitate removal. The cases under review are those of adults in detention, in whom the swallowing of large, irregular, and ill-assorted articles is the main feature. Only 3 cases are reported as accidental, and concern the loss of two needles and a small denture.

\section{Psychology of the Intentional Swallower}

The psychological aspect of the intentional swallower is interesting, and varies in type with the environment and mode of life. In all there is an underlying psychological framework of egoism, vanity, and self-attention.

From time immemorial this faculty has been utilized as a means of livelihood in exhibitions such as the swallowing of a sword, watch, or live goldfish-duly returned unharmed from their immersion in the stomach. Proof of the last-named performance was given a few years ago at a medical society in London, where an astute radiologist inserted some small lead shot inside each fish - through its mouth-so that their movements in the performer's stomach could be observed with the 